\title{
SENSORLESS CONTROL OF A THREE-SECTION PERMANENT MAGNET VALVE ELECTRIC MOTOR
}

V.N. Enin

A.V. Stepanov enin@bmstu.ru

stepanov.bmstu@gmail.com

\section{Bauman Moscow State Technical University, Moscow, Russian Federation}

\begin{abstract}
A method of sensorless control of a three-section valve electric motor with 120-degree commuting windings is proposed. The commuting of the windings is carried out when the back-EMF of the section to be disconnected and connected is equal; the third section is connected to a constant voltage source. In this case, the electromagnetic torque of the motor varies slightly. The commuting times are determined using a function depending on the ratio of backEMF of the section to be disconnected and connected. This function does not depend on the rotational frequency and can be used in a wide range of speeds. The angle of rotation of the rotor and the rotational frequency for controlling the motor are determined after converting the equations of the motor to a twophase system. An example of starting the motor with the transition to a sensorless control system commuting windings is given. The effectiveness and efficiency of the method are confirmed by modeling a low-power three-section valve electric motor in the MATLAB\&Simulink system using the SimPowersystems extension
\end{abstract}

\section{Keywords}

Three-section valve electric motor, sensorless control, back-EMF, flux linkage, MATLAB\&Simulink

Received 09.01.2019

(C) Author(s), 2019

Introduction. Due to their compactness, reliability, efficiency, and low cost, electric valve motors are increasingly used in instrument making, aircraft control and navigation systems [1-4]. The development of power electronics and semiconductor technologies has led to the creation of a new element base of intelligent integrated circuits. Such integrated circuits contain not only power electronic components (diodes, transistors), but also power device control elements - drivers. This allows the implementation of complex control algorithms for valve electric motors. To control the keys, it is necessary to determine the position of the motor rotor. Traditionally, the rotor position is determined using a rotor position sensor (RPS), which makes the motor design 
more complicated. Environmental conditions (temperature, humidity, vibrations, smoke, radiation) affect the sensor's performance, as a result of which the cost of the electric drive rises and reliability decreases. Another approach is based on the recently intensively developed methods of sensorless control of commuting the windings of valve motors, which reduces the cost of the electric drive and increases its reliability. Most of the research on the development of sensorless control of the commuting of windings of valve motors are based on the analysis of the back-EMF of motor rotation [5-8]. The rotor position is determined by the zero crossings of the back-EMF of the motor rotation, which is calculated from the voltage at the terminals of the electric motor and the current in the motor windings [5]. Commuting is carried out through 30 electrical degrees after passing the back-EMF of rotation through zero. The error in determining the moment of commutation of sections of a brushless DC motor (BLDC) can lead to unreliable operation of the electric drive, especially at high speeds of rotation of the rotor. In this regard, several works are devoted to the development of methods for correcting the error moments of commuting sections of the motor. The method of back-EMF of rotation is developed in Ref. [7] for non-ideal back-EMF and an adaptive method of compensation of commutation errors based on the analysis of back-EMF at the moments of the section on and off is proposed. A method for determining the position of the rotor, based on the analysis of the third harmonic back-EMF, was proposed in Ref. [8]. This method is not applicable to all types of valve motors since it requires a specific motor design. Methods based on the analysis of back-EMF of rotation have a disadvantage, namely, the back-EMF of rotation depends on the speed of rotation of the rotor, which makes it difficult to determine commuting points in a wide range of speeds of rotation of the rotor. To determine the moment of commutation in the works [9-11], a function (called the G-function) is used, which is the ratio of the back-EMF of the sections calculated from the current and voltage of the sections. Based on this function, at the moments when it is necessary to carry out the commuting of sections, pulses are formed when the zero is crossed by the denominator of the function. The resulting signal contains noise and a high-frequency component created by the operation of the diodes. This noise must be eliminated by a low-pass filter. To determine the commuting points, the value of the pulse generated by the function is analyzed. If the value of the pulse exceeds a certain threshold, then the sections are commutated. The threshold value affects the reliability of determining the moments of commuting. If the threshold is low, spurious signal shaping is possible for commuting sections, and if it is too high, skipping of commuting points is possible. The strategy of starting the motor with 
sensorless BLDC control, based on the determination of the rotor position at zero speed, was proposed in Ref. [12]. The method of sensorless control of twosection BLDC, based on the analysis of the function, which does not depend on the speed of rotation and generates pulses with equal back-EMF of rotation of the first and second sections, was developed in Ref. [13]. These pulses and carried out the commuting sections. Despite numerous studies on the development of methods for sensorless control of BLDC, the issues of reliability and accuracy of the proposed methods for starting the motor and operating in a wide range of speeds require further research.

This paper proposes a method for sensorless control of the commuting windings of a three-section valve motor. The case of 120-degree commutation and wye winding with an isolated common point is considered. Commuting sections is carried out with equal back-EMF disconnected and connected sections. The electric equilibrium equations for the three sections of the motor are converted to a fixed coordinate system $\alpha, \beta$. The moments of commuting sections are determined by the ratio of two back-EMF of rotation in a fixed system of coordinates $\alpha, \beta$. These back-EMFs are the calculated angle of rotation of the rotor and the instantaneous speed of rotation of the rotor. Conversion to a two-phase system allows not only to determine the moments of commuting, but also the instantaneous speed of rotation.

Mathematical model of a three-section electric valve motor. The power supply circuit of the windings of a three-section, brushless DC motor by an electronic commutator on field-effect transistors is given in Fig. 1 [1].

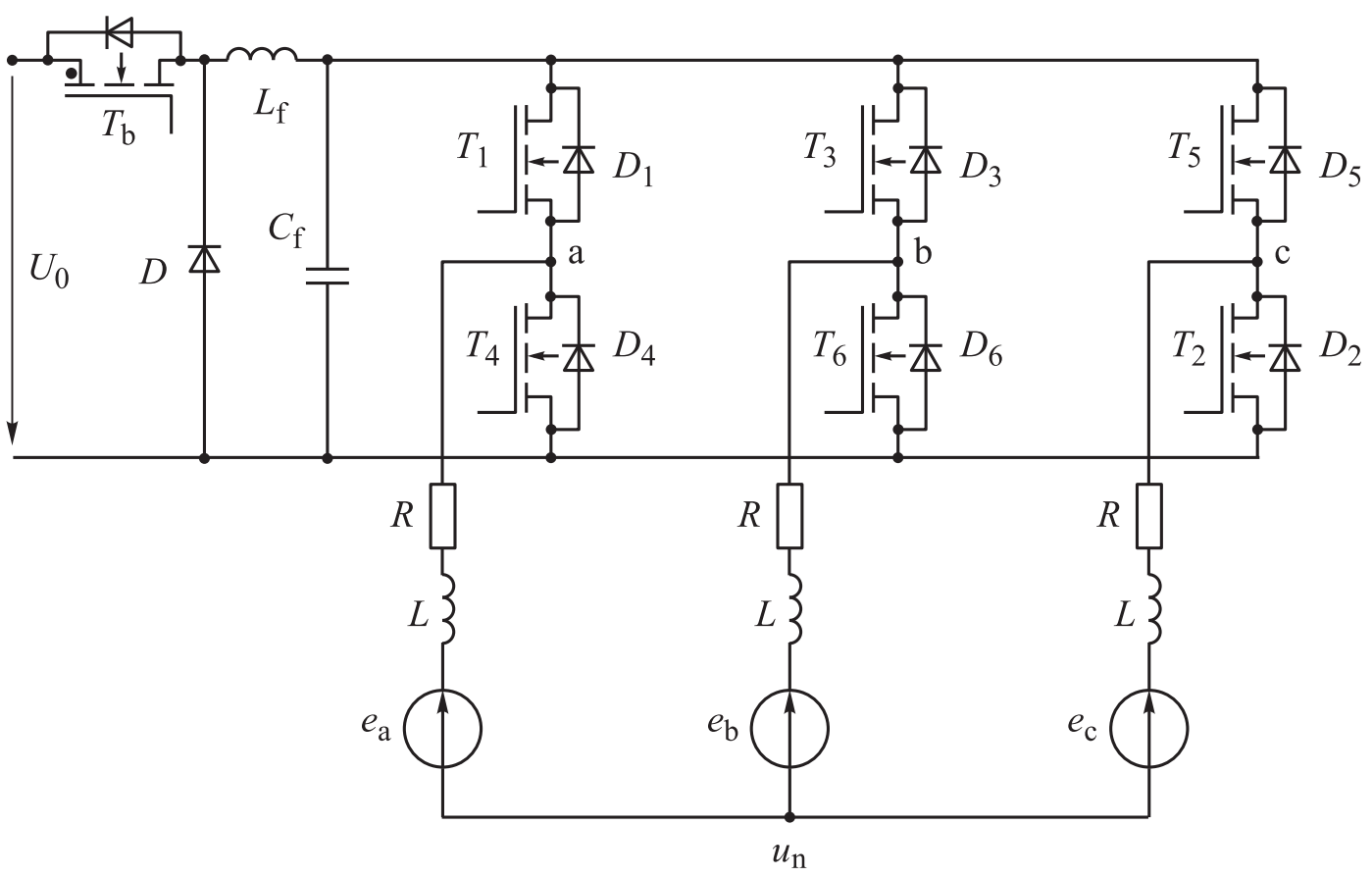

Fig. 1. Three-section BDCM winding power supply circuit 
The equations in the phase coordinates for the sections of BLDC motor with permanent magnets taking into account the mutual inductances of the sections have the form (the case of an implicit pole rotor is considered):

$$
\left[\begin{array}{ccc}
R_{\mathrm{s}} & 0 & 0 \\
0 & R_{\mathrm{s}} & 0 \\
0 & 0 & R_{\mathrm{s}}
\end{array}\right]\left[\begin{array}{c}
i_{\mathrm{a}} \\
i_{\mathrm{b}} \\
i_{\mathrm{c}}
\end{array}\right]+\left[\begin{array}{ccc}
L_{\mathrm{s}} & -M_{\mathrm{s}} & -M_{\mathrm{s}} \\
-M_{\mathrm{s}} & L_{\mathrm{s}} & -M_{\mathrm{s}} \\
-M_{\mathrm{s}} & -M_{\mathrm{s}} & L_{\mathrm{s}}
\end{array}\right]\left[\begin{array}{c}
\frac{d i_{\mathrm{a}}}{d t} \\
\frac{d i_{\mathrm{b}}}{d t} \\
\frac{d i_{\mathrm{c}}}{d t}
\end{array}\right]+\left[\begin{array}{c}
e_{\mathrm{a}} \\
e_{\mathrm{b}} \\
e_{\mathrm{c}}
\end{array}\right]=\left[\begin{array}{l}
u_{\mathrm{a}}-u_{\mathrm{n}} \\
u_{\mathrm{b}}-u_{\mathrm{n}} \\
u_{\mathrm{c}}-u_{\mathrm{n}}
\end{array}\right],
$$

where $R_{\mathrm{s}}$ is active resistance of section stator winding; $i_{\mathrm{a}}, i_{\mathrm{b}}, i_{\mathrm{c}}$ are currents in the windings of the stator sections; $L_{\mathrm{s}}$ is inductance winding sections; $M_{\mathrm{s}}$ is mutual inductance of the windings of the sections; $e_{\mathrm{a}}, e_{\mathrm{b}}, e_{\mathrm{c}}$ are back-EMF of the stator windings; $u_{\mathrm{a}}, u_{\mathrm{b}}, u_{\mathrm{c}}$ are voltage applied to the windings of sections; $u_{\mathrm{n}}$ is neutral point voltage. In wye connection without neutral $i_{\mathrm{a}}+i_{\mathrm{b}}+i_{\mathrm{c}}=0$. It is assumed $e_{\mathrm{a}}+e_{\mathrm{b}}+e_{\mathrm{c}}=0$, then

$$
u_{\mathrm{n}}=\frac{u_{\mathrm{a}}+u_{\mathrm{b}}+u_{\mathrm{c}}}{3} .
$$

Let us define the inductance of the stator along the longitudinal and transverse axes $L_{\mathrm{d}}=L_{\mathrm{q}}$ and the inductance $L_{0}$ for the zero sequence. The phase inductances of the windings of the sections in the rotating coordinate system $d, q$ are defined as follows: $L_{\mathrm{s}}=\left(L_{0}+2 L_{\mathrm{d}}\right) / 3 ; M_{\mathrm{s}}=\left(L_{\mathrm{d}}-L_{0}\right) / 3$. Let us move from the equations in phase coordinates to the mathematical model of the machine in a fixed coordinate system $\alpha, \beta$ based on the transformation (a particular form of the transformation matrix E. Clarke) [14]

$$
\left[\begin{array}{l}
u_{\alpha} \\
u_{\beta}
\end{array}\right]=T\left[\begin{array}{l}
u_{\mathrm{a}} \\
u_{\mathrm{b}} \\
u_{\mathrm{c}}
\end{array}\right] .
$$

Here $\left[u_{\alpha}, u_{\beta}\right]^{t}$ is a two-dimensional column vector of stator windings voltages in the fixed coordinate system $\alpha, \beta$; $T$ is a rectangular transformation matrix from phase coordinates to coordinates $\alpha, \beta ;\left[u_{\mathrm{a}}, u_{\mathrm{b}}, u_{\mathrm{c}}\right]^{\mathrm{t}}$ is column vector of stator windings voltages in phase coordinates. Transformation matrix

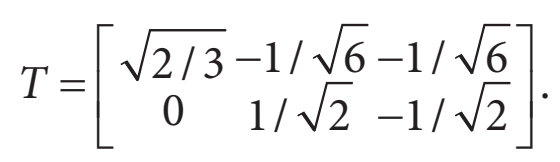

The inverse transition from state coordinates in a fixed coordinate system to phase voltages or currents is based on the inverse transformation 


$$
\left[\begin{array}{l}
u_{\mathrm{a}} \\
u_{\mathrm{b}} \\
u_{\mathrm{c}}
\end{array}\right]=T^{-1}\left[\begin{array}{l}
u_{\alpha} \\
u_{\beta}
\end{array}\right],
$$

where $T^{-1}$ is inverse transition matrix from coordinates $\alpha, \beta$ to phase coordinates,

$$
T^{-1}=\left[\begin{array}{cc}
\sqrt{2 / 3} & 0 \\
-1 / \sqrt{2} & 1 / \sqrt{2} \\
-1 / \sqrt{6} & 1 / \sqrt{2}
\end{array}\right]
$$

For the transformation matrix $T$, the following equality holds: $T^{-1}=T^{\mathrm{t}}\left(T^{\mathrm{t}}\right.$ is the transposed matrix). Multiplying the electric equilibrium system (1) on the left by the transformation matrix $T(2)$ and expressing the currents $i_{\mathrm{a}}, i_{\mathrm{b}}, i_{\mathrm{c}}$ using the inverse transformation (3), we get

$$
\left[\begin{array}{cc}
R_{\mathrm{s}} & 0 \\
0 & R_{\mathrm{s}}
\end{array}\right]\left[\begin{array}{c}
i_{\alpha} \\
i_{\beta}
\end{array}\right]+\left[\begin{array}{cc}
L & 0 \\
0 & L
\end{array}\right]\left[\begin{array}{c}
\frac{d i_{\alpha}}{d t} \\
\frac{d i_{\beta}}{d t}
\end{array}\right]+\left[\begin{array}{c}
e_{\alpha} \\
e_{\beta}
\end{array}\right]=\left[\begin{array}{c}
u_{\alpha \mathrm{n}} \\
u_{\beta \mathrm{n}}
\end{array}\right] .
$$

Here $L=L_{\mathrm{s}}+M_{\mathrm{s}}$. Back-EMF sections at a constant rotational speed vary according to the law $e_{\mathrm{a}}(\theta)=-\omega_{\mathrm{e}} \psi_{\mathrm{m}} \sin \theta, e_{\mathrm{b}}(\theta)=-\omega_{\mathrm{e}} \psi_{\mathrm{m}} \sin (\theta-\rho), e_{\mathrm{c}}(\theta)=$ $=-\omega_{\mathrm{e}} \psi_{\mathrm{m}} \sin (\theta-\rho)$, where $\omega_{\mathrm{e}}$ is the angle rotor speed; $\psi_{\mathrm{m}}$ is the maximum flux linkage of the section created by the permanent magnet of the rotor; $\theta$ is the back-EMF phase; $\rho=2 \pi / 3$.

Back-EMF sections in a fixed coordinate system $\alpha, \beta$ :

$$
\begin{aligned}
& e_{\alpha}(\theta)=-3 / \sqrt{2} \omega_{\mathrm{e}} \psi_{\mathrm{m}} \sin \theta ; \\
& e_{\beta}(\theta)=-\sqrt{3 / 2} \omega_{\mathrm{e}} \psi_{\mathrm{m}} \cos \theta .
\end{aligned}
$$

The dependence of the back-EMF in phase coordinates is shown in Fig. 2. Electromagnetic moment in the fixed coordinate system $\alpha, \beta$ :

$$
M=i_{\beta} \psi_{\alpha}(\theta)-i_{\alpha} \psi_{\beta}(\theta) \text {. }
$$

Next, we consider the 120-degree commutation of the sections of the rotor windings, at which two sections operate simultaneously, and one of the sections is disconnected from the source.

Method of sensorless commuting of sections of a valve motor with permanent magnets. At 120-degree commuting, one of the sections that were connected to the source during the previous commuting, we call the working 
section, and we denote its back-EMF as $e_{\mathrm{w}}(\theta)$. Back-EMF section, disconnected during the next commuting, we denote $e_{\mathrm{on}}(\theta)$, the back-EMF section, connected in the next commuting, $e_{\text {off }}(\theta)$. Then the transition to a fixed coordinate system $\alpha, \beta$, can be done as

$$
\begin{gathered}
e_{\alpha}(\theta)=\sqrt{\frac{2}{3}} e_{\mathrm{w}}(\theta)-\sqrt{\frac{1}{6}} e_{\mathrm{on}}(\theta)-\sqrt{\frac{1}{6}} e_{\mathrm{off}}(\theta) ; \\
e_{\beta}(\theta)=\sqrt{\frac{1}{2}} e_{\mathrm{on}}(\theta)-\sqrt{\frac{1}{2}} e_{\mathrm{off}}(\theta) .
\end{gathered}
$$
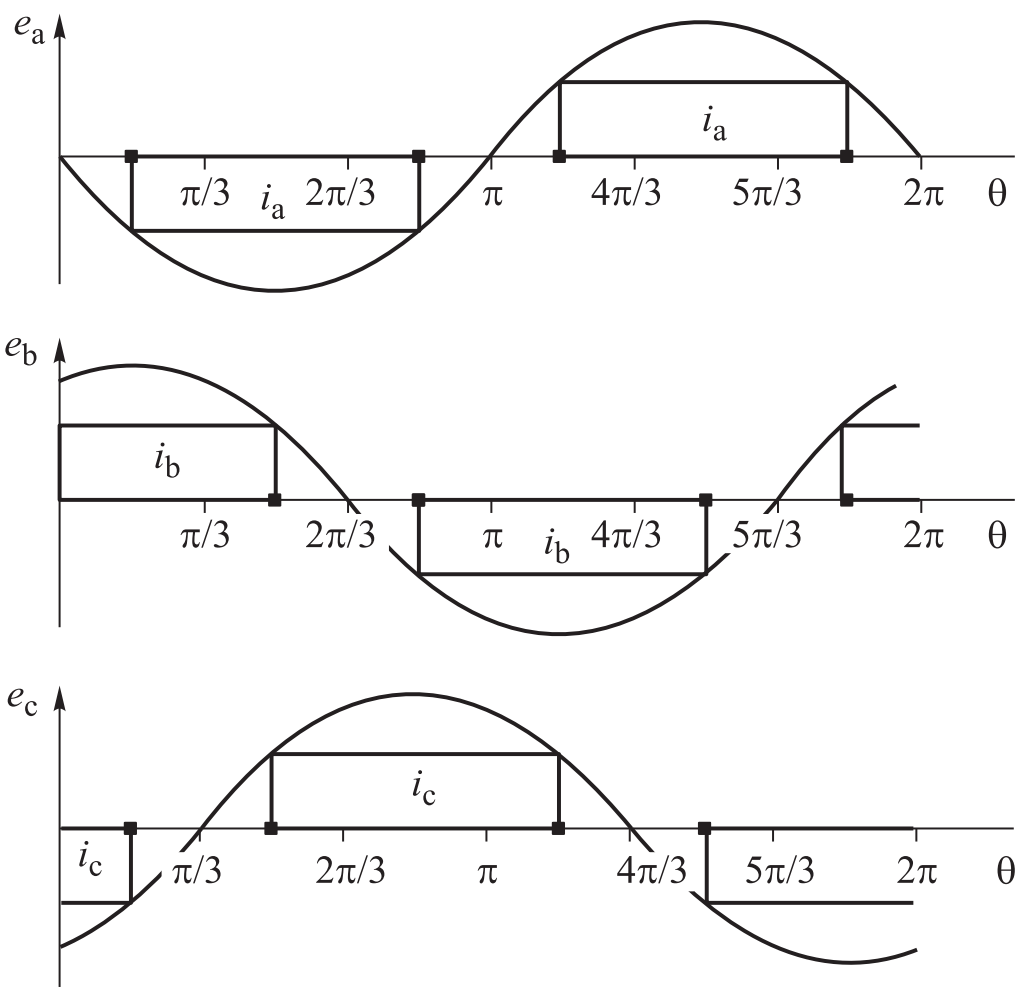

Fig. 2. Dependence of the back-EMF in phase coordinates (- section-commutating angles)

When commuting sections of stator windings, taking into account (6), (7), we use a function that represents the ratio of back-EMF stator sections in the fixed coordinate system $\alpha, \beta$ :

$$
H(\theta)=\frac{e_{\alpha}(\theta)}{e_{\beta}(\theta)} .
$$

At the moment of commuting, the back-EMF of the connected section must be equal to the back-EMF of the disconnected section, at this moment the function $H(\theta)$ (8) takes an infinite value. Then, setting a certain threshold 
value $H_{\mathrm{t}}$, the commuting will be carried out when the modulo function $H(\theta)$ exceeds the threshold value. Then the connected section with back-EMF $e_{\text {on }}(\theta)$ is disconnected from the source, and the section disconnected from the back-EMF $e_{\mathrm{off}}(\theta)$, is connected to the output of the voltage source. At the next intercommutation interval, taking into account $e_{\mathrm{w}(k+1)}(\theta)=e_{\mathrm{off}(k)}(\theta)$, $e_{\mathrm{on}(k+1)}(\theta)=e_{\mathrm{W}(k)}(\theta), \quad e_{\mathrm{off}(k+1)}(\theta)=e_{\mathrm{on}(k)}(\theta)$. Taking into account relations $(4)$, (5), the angle at the intercommutation interval can be determined

$$
\operatorname{tg} \theta=-\frac{e_{\alpha}(\theta)}{e_{\beta}(\theta)}=\frac{\sin \theta}{\cos \theta} .
$$

The dependences of back-EMF in the coordinate system $\alpha, \beta$ are shown in Fig. 3, while back-EMF $e_{\mathrm{w}}(\theta)$ is taken as back-EMF phase a, back-EMF $e_{\mathrm{on}}(\theta)$ is phase $b$, and back-EMF $e_{\text {off }}(\theta)$ is phase $c$.

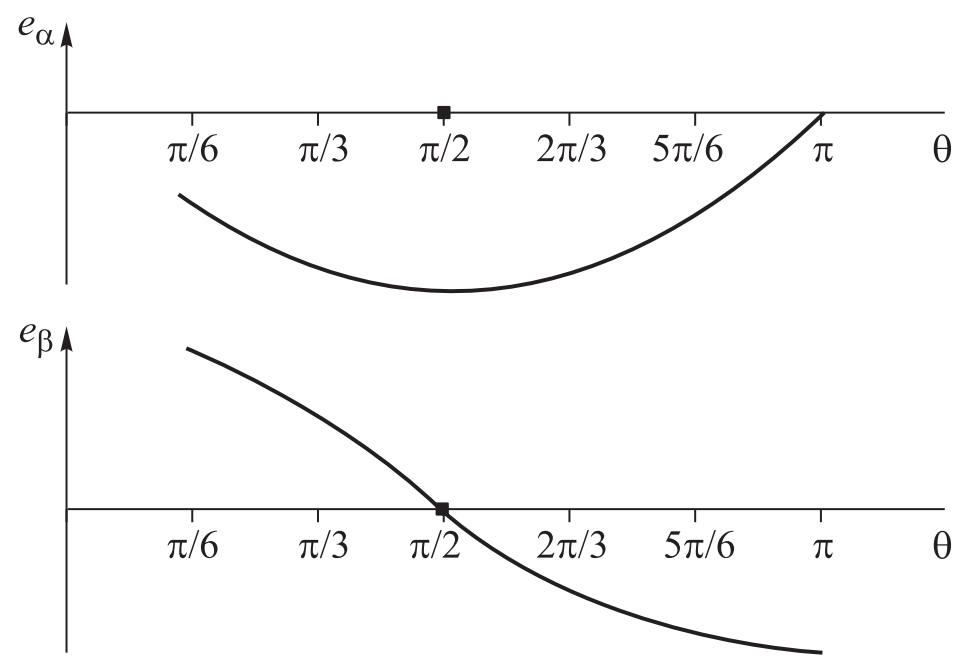

Fig. 3. Dependences of back EMF on the intercommutation interval in the fixed coordinate system $\alpha, \beta$

Back-EMF in the coordinate system $\alpha, \beta$ are calculated by the expressions

$$
\begin{aligned}
& e_{\alpha}(\theta)=u_{\alpha}-R_{s} i_{\alpha}-L \frac{d i_{\alpha}}{d t} ; \\
& e_{\beta}(\theta)=u_{\beta}-R_{s} i_{\beta}-L \frac{d i_{\beta}}{d t} .
\end{aligned}
$$

In the calculations using formula (9), difficulties arise if the denominator $\cos \theta$ is close to zero. Therefore, to improve the accuracy of determining the angle $\theta$, it is advisable to calculate the increment of the angle $\Delta \theta$. In this case, the value of $\cos \Delta \theta$ is close to unity. Let $y_{s}=\sin (\theta-\Delta \theta), y_{c}=\cos (\theta-\Delta \theta)$, then 


$$
\begin{aligned}
& y_{\mathrm{s}}=\sin \theta \cos \Delta \theta+\cos \theta \sin \Delta \theta ; \\
& y_{\mathrm{c}}=\cos \theta \cos \Delta \theta-\sin \theta \sin \Delta \theta .
\end{aligned}
$$

Solving this system with respect to $\sin \Delta \theta$ and $\cos \Delta \theta$, we obtain

$$
\begin{aligned}
& \sin \Delta \theta=\frac{y_{s} \cos \theta-y_{c} \sin \theta}{\sin ^{2} \theta+\cos ^{2} \theta} ; \\
& \cos \Delta \theta=\frac{y_{s} \sin \theta+y_{c} \cos \theta}{\sin ^{2} \theta+\cos ^{2} \theta} .
\end{aligned}
$$

Given (10), (11), the increment of the rotation angle of the rotor at the intercommutation interval is advisable to calculate on the basis of the ratio

$$
\operatorname{tg} \Delta \theta=\frac{e_{\beta}(\theta-\Delta \theta) e_{\alpha}(\theta)-e_{\alpha}(\theta-\Delta \theta) e_{\beta}(\theta)}{e_{\alpha}(\theta-\Delta \theta) e_{\alpha}(\theta)-e_{\beta}(\theta-\Delta \theta) e_{\beta}(\theta)} .
$$

The calculation of the increment of the angle of rotation of the rotor according to the formula (12) has the advantage since the ratio of back-EMF does not depend on the frequency of rotation of the rotor and can be used in a wide range of speed values.

Simulation and computational experiment results. To substantiate and study the effectiveness of the proposed sensorless control algorithm for a valve motor, a brushless low-power electric motor of the Permanent Magnet Motor (PMM) type was simulated. The simulation was performed using the MATLAB\&Simulink system and models of a three-section brushless motor and a power semiconductor bridge commutator of the SimPowerSystems expansion. As a mathematical model of the motor, a model of the Permanent Magnet Synchronous Machine from the library of blocks SimPowerSystems was used. A motor is an electric machine with a three-section winding on the stator and a multi-pole rotor with permanent magnets. The number of pole pairs is 4 . The resistance and inductance of the stator sections is $R_{\mathrm{S}}=6 \Omega, L_{\mathrm{S}}=0.42 \cdot 10^{-3} \mathrm{H}$. It is assumed that the shape of the back-EMF stator sections is close to sinusoidal. The supply voltage of the constant source is $27 \mathrm{~V}$. Sections of the stator windings are connected in a wye. The functional diagram of the sensorless control of the commutating of the winding of a three-section BLDC motor is shown in Fig. 4.

When the rotor rotates in the stator windings, an EMF is induced, the value of which can be calculated from the voltages $u_{\mathrm{a}}, u_{\mathrm{b}}, u_{\mathrm{c}}$ applied to the sec- 


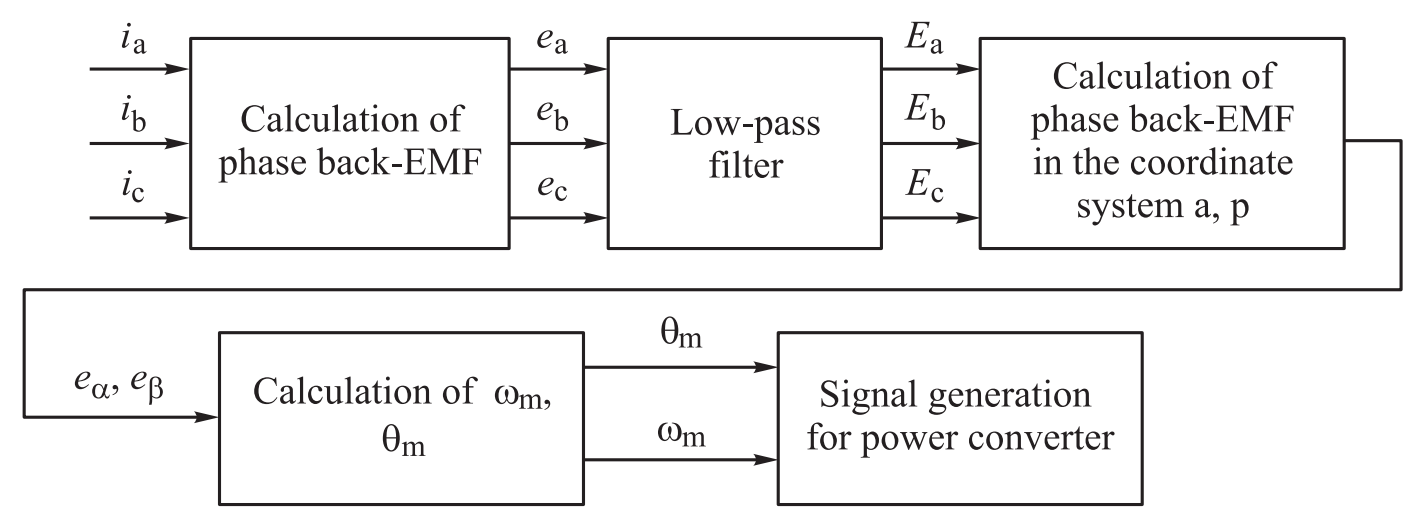

Fig. 4. Functional control circuit for commuting windings of three-section BLDC motor

tions and currents of the sections $i_{\mathrm{a}}, i_{\mathrm{b}}, i_{\mathrm{c}}$. The commuting of the windings is carried out with equal back-EMF rotation of the disconnected and connected phases (120-degree commuting is considered). In the dependences of the backEMF on time, calculated from the phase voltages and currents of the sections, pulses are generated as a result of the operation of the keys of the power semiconductor converter. After calculating the back-EMF, these pulses are smoothed by a low-pass filter. Phase back-EMF $e_{\mathrm{a}}(t), e_{\mathrm{b}}(t), e_{\mathrm{c}}(t)$ calculate back-EMF in a fixed coordinate system $e_{\alpha}(t), e_{\beta}(t)$, which is used to determine the angular electric velocity $\omega_{\mathrm{e}}$, the angular velocity of rotation of the rotor $\omega_{\mathrm{m}}=\omega_{\mathrm{e}} / p$. In calculating the instantaneous angular velocity, relation (12) is used, and to determine the back-EMF in a stationary system with a phase shift of $e_{\alpha}(t-\Delta t), e_{\beta}(t-\Delta t)$ is a delay line. After determining the increment of the angle $\Delta \theta$, the instantaneous angular velocity $\omega_{\mathrm{e}}=\Delta \theta / \Delta t$ is found. The angle of rotation of the rotor is determined by the integration of the angular velocity. A decrease in the delay time $\Delta t$ leads to an increase in the error in determining the instantaneous velocity and the angle of rotation of the rotor. The functional diagram for calculating the instantaneous angular velocity and the angle of rotation of the rotor is shown in Fig. 5.

The commuting moments of the stator windings are determined by the angle of rotation of the rotor, which at the moments of commuting must be equal to $\theta_{c}=k(\pi / 12), k=1,2, \ldots, m$. At these points in time, pulses appear which are shown in oscillograms of phase back-EMF rotor windings (Fig. 6) obtained in the simulation. Impulses in back-EMF rotation dependencies complicate the determination of the commuting angles of the stator windings. To reduce the influence of pulses from the operation of a semiconductor converter, a low-pass filter is used. 


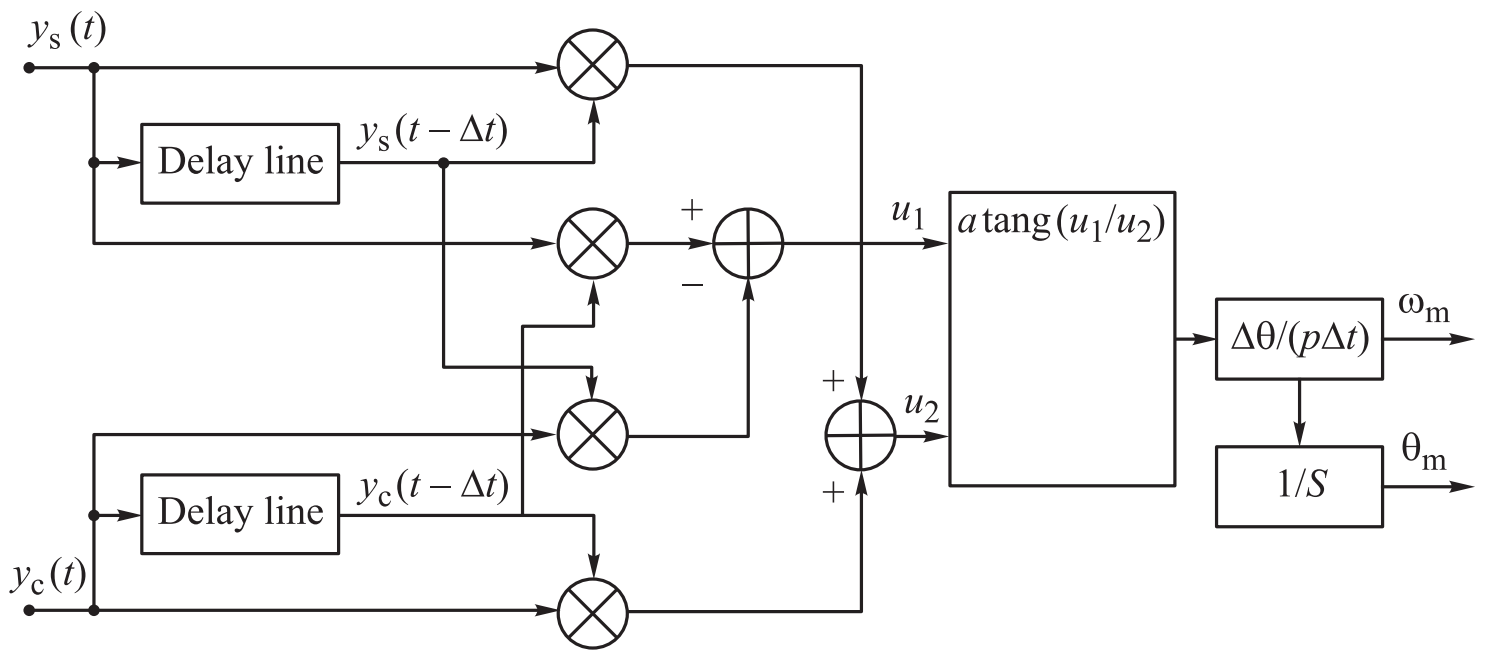

Fig. 5. Functional diagram for calculating the instantaneous angular velocity and the rotation angle of the rotor

BEMF a, V

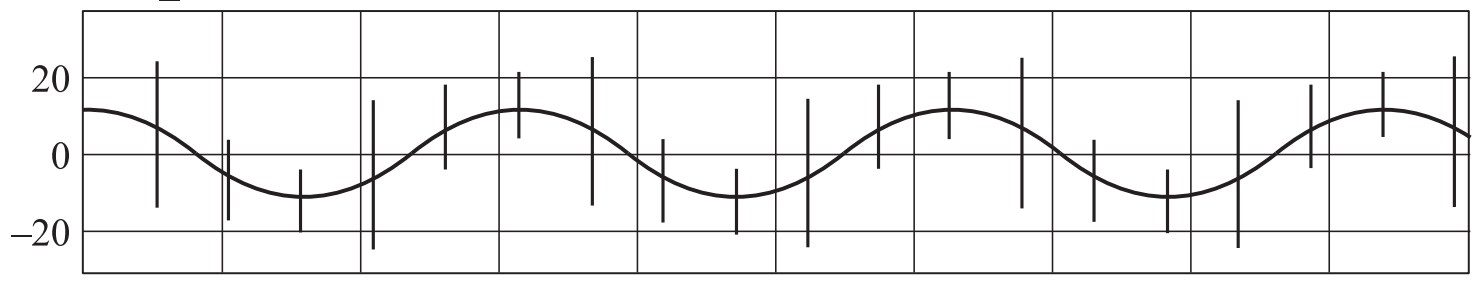

BEMF_b, V

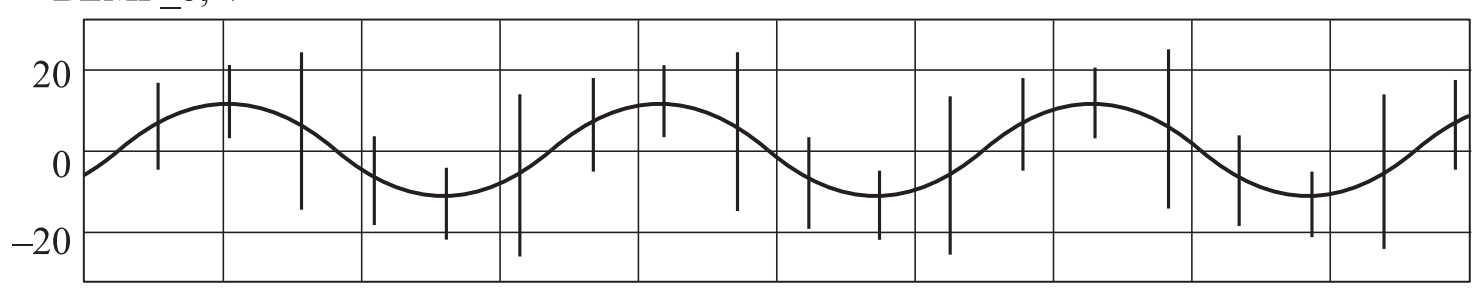

BEMF_c, V

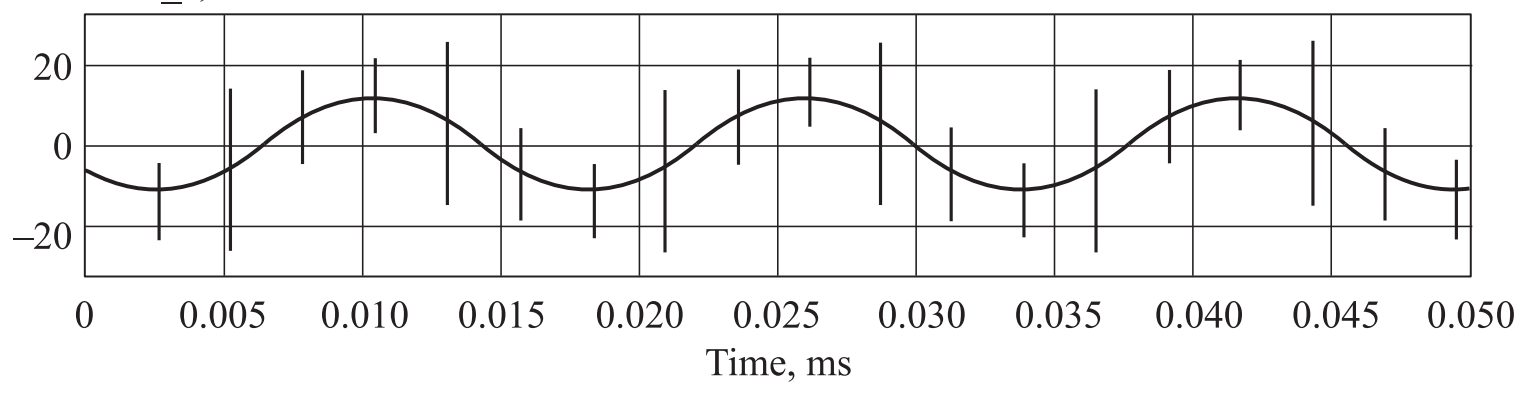

Fig. 6. Oscillograms of phase back-EMF rotation

The dependences of the phase back-EMF rotation after passing through the low-pass filter are shown in Fig. 7. After passing the signals of the phase back-EMF low-pass filter, calculate back-EMF $e_{\alpha}(t), e_{\beta}(t)$ in the fixed coordinate system $\alpha, \beta$ (Fig. 8). 


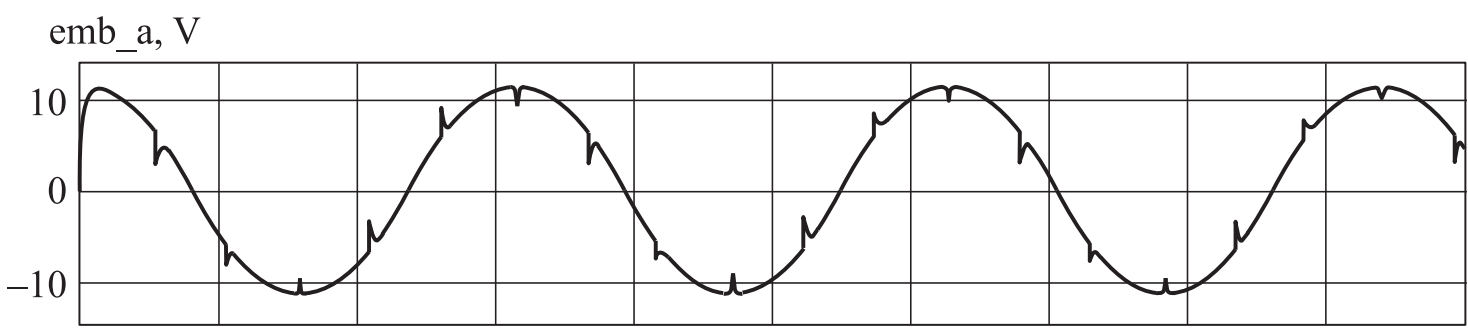

emb_b, V

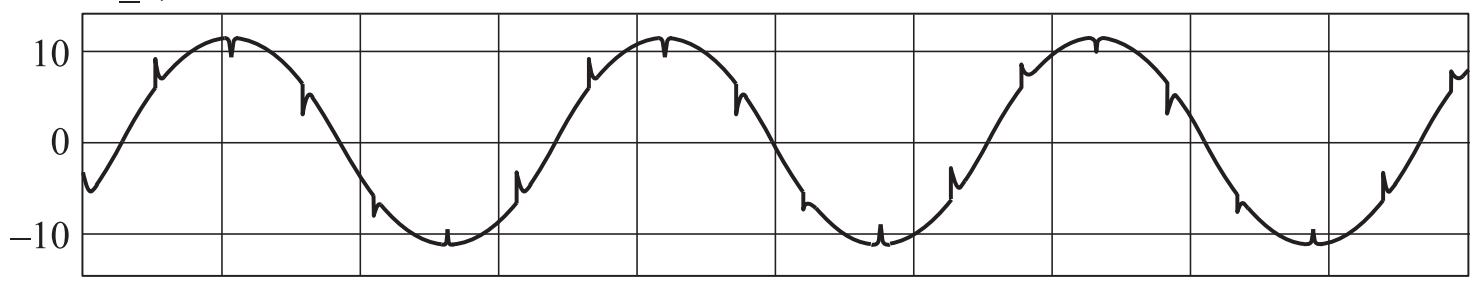

emb_c, V

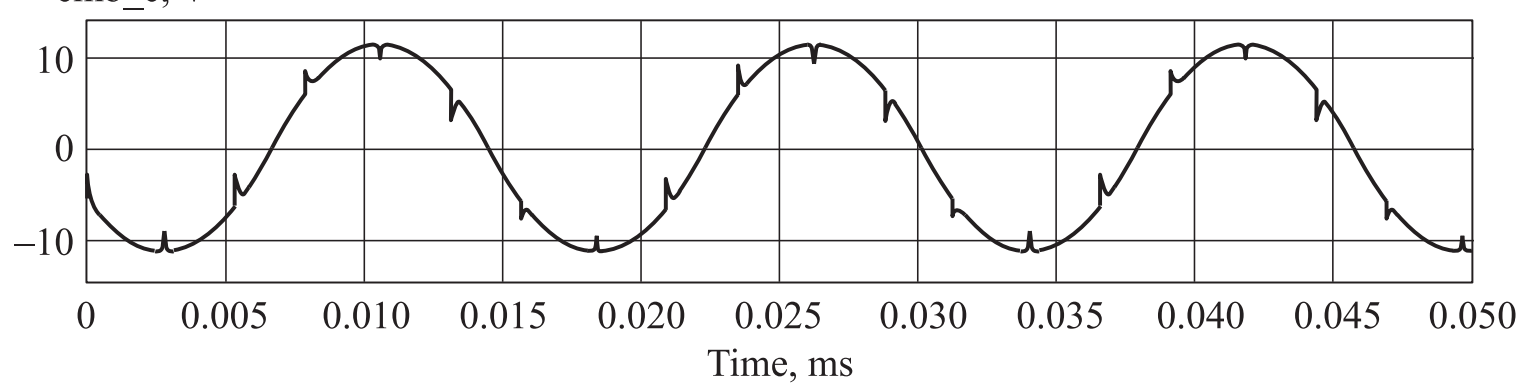

Fig. 7. Dependences of phase back-EMF rotation after passing the low-pass filter

BEMB_alfa, rad

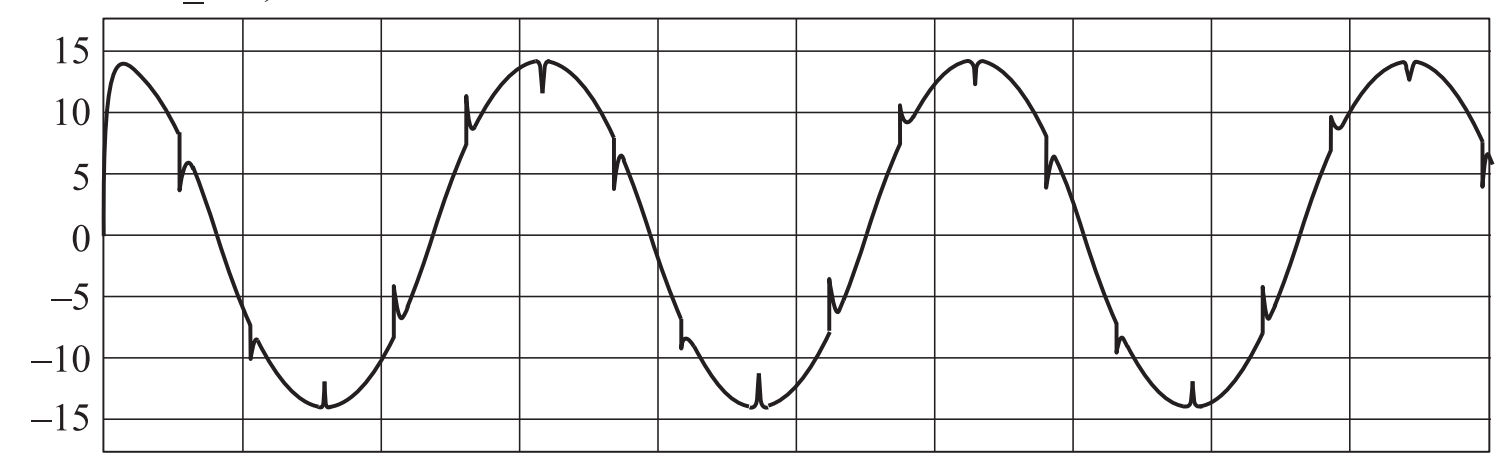

BEMB_beta, rad

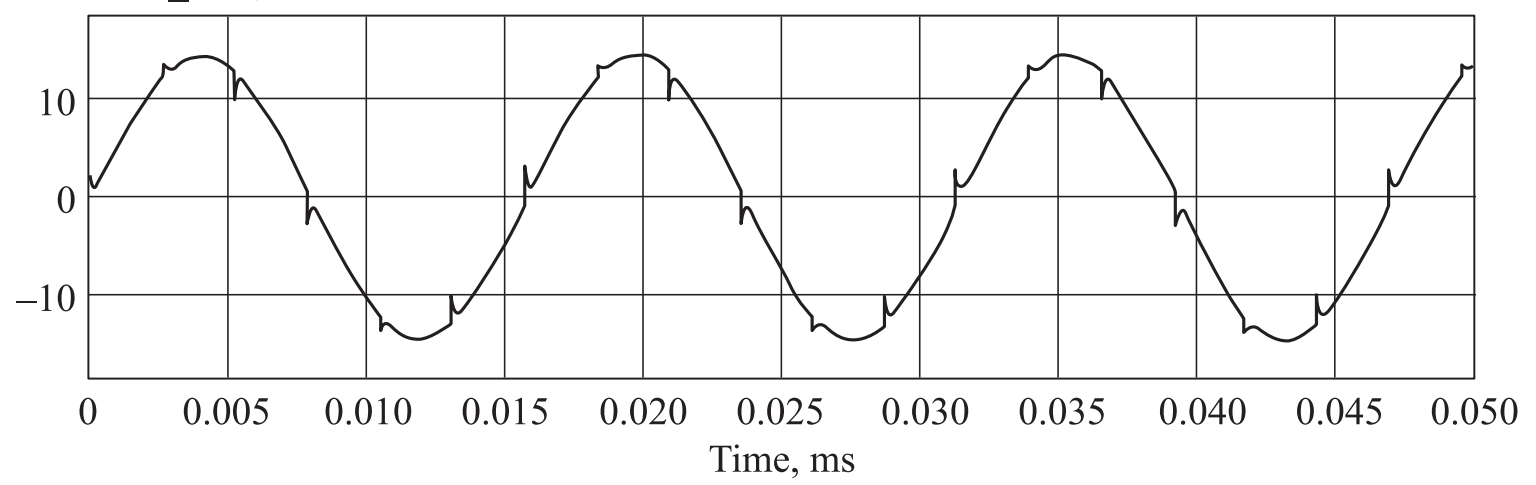

Fig. 8. Dependences of phase back-EMF rotation in the fixed coordinate system $\alpha, \beta$ 
The simulation of the electric motor when operating at a constant speed. The delay $\Delta t$ in calculating the instantaneous speed and the angle of rotation of the rotor using relations (10)-(12) is set to $0.05 \mathrm{~ms}$. The simulation results are the dependences of the rotation angle of the rotor and the electromagnetic torque of the motor at a rotational speed of $1000 \mathrm{r} / \mathrm{m}$ on time are shown in Fig. 9.

theta_m, rad

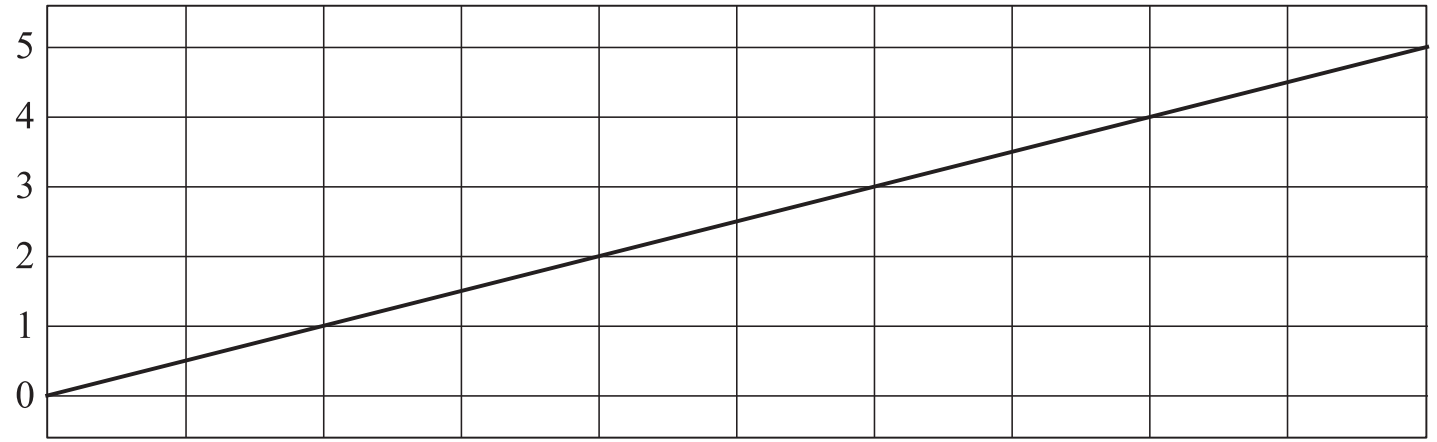

torque, $\mathrm{nm}$

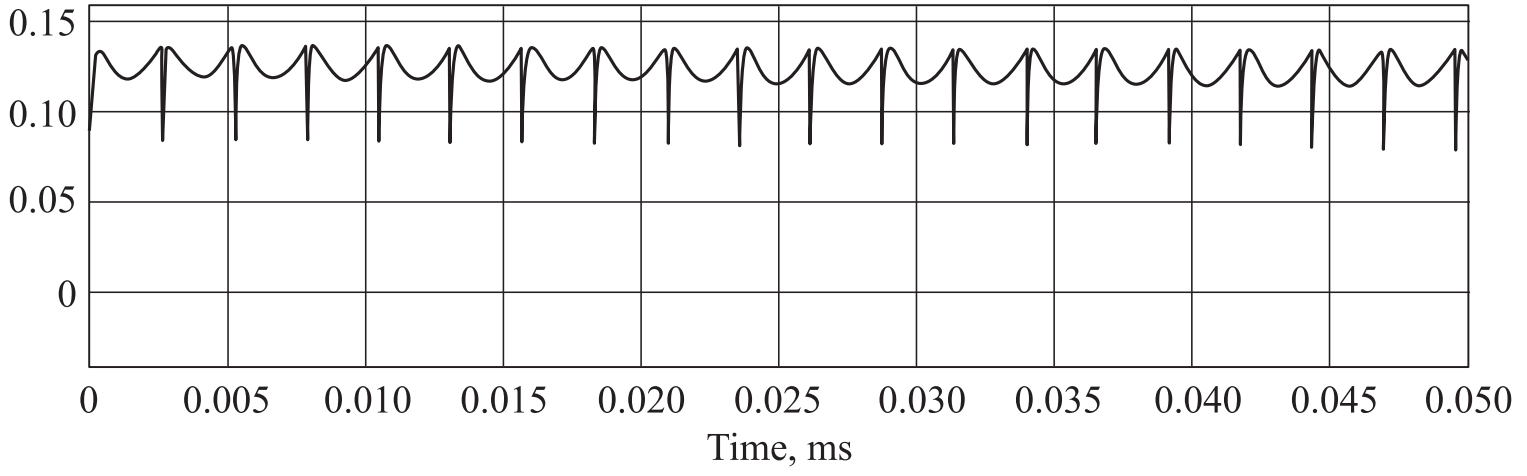

Fig. 9. Dependences of the angle of rotation of the rotor and the electromagnetic moment of the motor at a frequency of rotation of $1000 \mathrm{r} / \mathrm{m}$ from time

The error $\varepsilon$ of determining the commuting angles by the proposed method, which was estimated as $\varepsilon=\max _{k}\left|\theta_{k}-\theta_{k}^{*}\right|, k=1,2, \ldots, m$, where $\theta_{k}$ are the commuting angles calculated in integrating the equations of the mathematical model of a valve motor with high accuracy, is investigated; $\theta_{k}^{*}$ is commuting angles determined by the proposed method. The results of the estimation of the error in determining the proposed method of commuting angles for different values of the rotor speed:

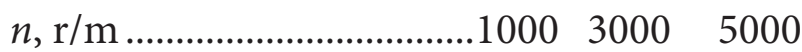

$$
\begin{aligned}
& \varepsilon \text {, deg ............................... 0,37 0,91 2,84 }
\end{aligned}
$$

When the motor is started, the low speed does not allow synchronizing the operation of the inverter keys in the case of sensorless commuting control. The error in determining the sensorless commuting angles at start-up reaches 
$\pi / 2$ rad. The performed computational experiments (simulation in the MATLAB\&Simulink system) showed that the proposed sensorless control algorithm provides an acceptable error in determining commuting angles at a reduced frequency up to $45 \mathrm{r} / \mathrm{m}$. In starting the motor, it is necessary to determine the position of the rotor, which is ensured by connecting two sections of the motor to a constant voltage source. The movement of the rotor is localized in the area of angles, which is determined by the load and the choice of connected sections, the magnitude and polarity of the voltage source. Then, a direct start is performed by applying to the section a sequence of rectangular voltage pulses. This strategy was used to simulate the launch and transition to sensorless BLDC motor control under load. The transition to sensorless control occurred after reaching the rotor speed of $45 \mathrm{r} / \mathrm{m}$ (Fig. 10).

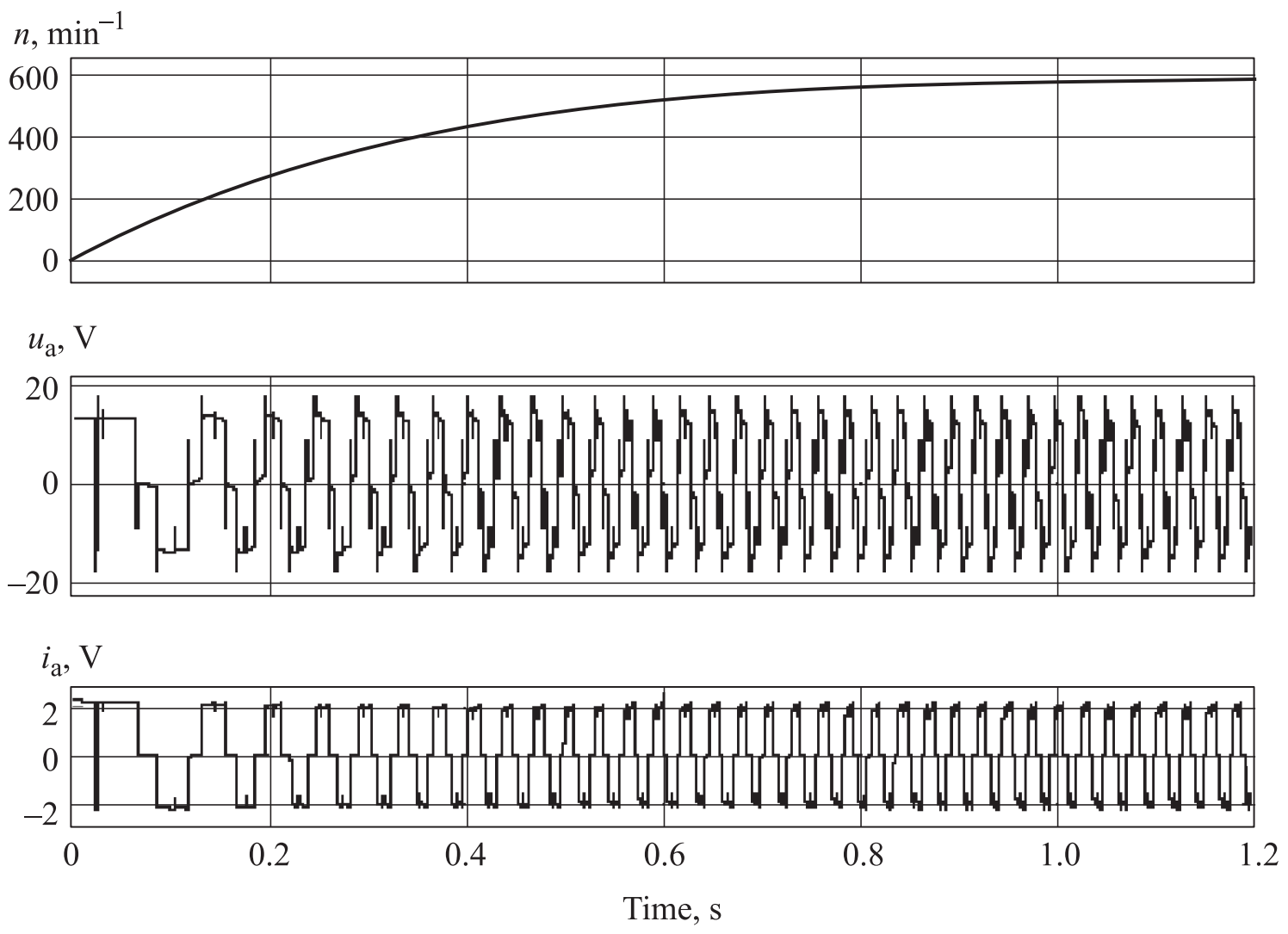

Fig. 10. Start-up and the transition to sensorless control

Conclusion. A method of sensorless determination of the commuting angles of a three-section permanent magnet valve motor and control of a power semiconductor converter is proposed. The sensorless control method is based on the transformation of the equations of a three-section motor when the wye windings connect to a two-phase system in a fixed coordinate system $\alpha, \beta$. Commuting angles are determined by calculating the back-EMF rotation in the fixed $\alpha, \beta$ system. At each stage of calculation, the increment of the rota- 
tion angle of the rotor is calculated using the ratio of the back-EMF $e_{\alpha}(\Delta \theta)$ and $e_{\beta}(\Delta \theta)$ increments. After calculating the angular velocity of rotation, integration determines the angle of rotation of the rotor. In the motor start-up mode, the described strategy allows you to commute to sensorless control after a small delay (in the example considered, the delay is $\approx 0.018 \mathrm{~s}$ ). The advantage of the proposed method is the independence of the ratio of the back-EMF sections of the rotor speed, which allows using it in a wide range of speeds and commuting to sensorless control at a low speed.

\section{REFERENCES}

[1] Arakelyan A.K., Afanasyev A.A. Ventilnye elektricheskie mashiny v sistemakh reguliruemogo elektroprivoda [Gated electric machines in systems of controlled electric drive]. Moscow, Vysshaya shkola Publ., 2006.

[2] Belkovskiy A.P., Tsatsenkin V.K. Pretsizionnyy elektroprivod s ventilnymi dvigatelyami [Precision electric drive with brushless DC electric motor]. Moscow, MEI Publ., 2010.

[3] Baranov M.V., Brodovskiy V.N., Zimin A.V., et al. Elektricheskie sledyashchie privody s momentnym upravleniem ispolnitelnymi dvigatelyami [Electric tracking drives with instantaneous control by actuating motors]. Moscow, BMSTU Publ., 2006.

[4] Solovyev V.A. Nepreryvnoe tokovoe upravlenie ventilnymi dvigatelyami [Continuous current control by brushless DC electric motors]. Moscow, MGTU im. A.N. Kosygina Publ., 2004.

[5] Niasar A.H., Vahedi A., Moghbelli H. A novel position sensorless control of a fourswitch, brushless DC motor drive without phase shifter. IEEE Trans. Power Electron., 2008, vol. 23, iss. 6, pp. 3079-3087. DOI: 10.1109/TPEL.2008.2002084

[6] Guo R.Ch., Mu Z., Li J.D. Research on position sensorless control system of highspeed brushless DC motor. 9th Int. Conf. Intelligent Human-Machine Systems and Cybernetics, 2017, pp. 62-65.

[7] Li H., Zheng Sh., Ren H. Self-correction of commutation point for high-speed sensorless BLDC motor with low inductance and nonideal back EMF. IEEE Trans. Power Electron., 2017, vol. 32, iss. 1, pp. 642-651. DOI: 10.1109/TPEL.2016.2524632

[8] Song X., Han B., Zheng Sh., et al. High-precision sensorless drive for high-speed BLDC motors based on the virtual third harmonic back-EMF. IEEE Trans. Power Electron., 2018, vol. 33, iss. 2, pp. 1528-1540. DOI: 10.1109/TPEL.2017.2688478

[9] Su G.-J., McKeever J.W. Low-cost sensorless control of brushless DC motors with improved speed range. IEEE Trans. Power Electron., 2004, vol. 19, iss. 2, pp. 296-302.

DOI: 10.1109/TPEL.2003.823174

[10] Chladny R.R., Koch Ch.R. Flatness-based tracking of an electromechanical variable valve timing actuator with disturbance observer feedforward compensation. IEEE Trans. Control Syst. Technol., 2008, vol. 16, iss. 4, pp. 652-663.

DOI: 10.1109/TCST.2007.912121 
[11] Chen Sh., Zxou X., Bai G., et al. Adaptive commutation error compensation strategy based on a flux linkage function for sensorless brushless DC motor drives in a wide speed range. IEEE Trans. Power Electron., 2018, vol. 33, iss. 5, pp. 3752-3754. DOI: 10.1109/TPEL.2017.2765355

[12] Liu G., Chen S., Zheng S., et al. Sensorless low-current start-up strategy of 100-kw BLDC motor with small inductance. IEEE Trans. Ind. Informat., 2017, vol. 13, iss. 3, pp. 1131-1140. DOI: 10.1109/TII.2016.2607158

[13] Enin V.N., Stepanov A.V. The commutation of BLDC motors in sensorless control via EMF of rotation. Herald of the Bauman Moscow State Technical University, Series Instrument Engineering, 2018, no. 6, pp. 87-101 (in Russ.).

DOI: 10.18698/0236-3933-2018-6-87-101

[14] Nos O.V. Vector-matrix models of a salient-pole synchronous machine with permanent magnets in terms of different state vector components. Izvestiya vuzov. Elektromekhanika [Russian Electromechanics], 2017, vol. 60, no. 6, pp. 5-10 (in Russ.).

Enin V.N. - Dr. Sc. (Eng.), Professor, Department of Electrical Engineering and Industrial Electronics, Bauman Moscow State Technical University (2-ya Baumanskaya ul. 5, str. 1, Moscow, 105005 Russian Federation).

Stepanov A.V. - Dr. Sc. (Eng.), Professor, Department of Electrical Engineering and Industrial Electronics, Bauman Moscow State Technical University (2-ya Baumanskaya ul. 5, str. 1, Moscow, 105005 Russian Federation).

\section{Please cite this article in English as:}

Enin V.N., Stepanov A.V. Sensorless control of a three-section permanent magnet valve electric motor. Herald of the Bauman Moscow State Technical University, Series Instrument Engineering, 2019, no. 5, pp. 20-34.

DOI: $10.18698 / 0236-3933-2019-5-20-34$ 